\title{
Emergence of pregnancy-related listeriosis amongst ethnic minorities in England and Wales
}

P Mook (Piers.mook@hpa.org.uk)¹, K A Grant ${ }^{1}$, C L Little ${ }^{1}$, G Kafatos ${ }^{1}$, I A Gillespie ${ }^{1}$

1. Health Protection Agency, Centre for Infections, London, United Kingdom

Citation style for this article:

Mook P, Grant KA, Little CL, Kafatos G, Gillespie IA. Emergence of pregnancy-related listeriosis amongst ethnic minorities in England and Wales. Euro Surveill.

2010;15(27):pii=19610. Available online: http://www.eurosurveillance.org/ViewArticle.aspx?Articleld=19610

Listeriosis is a rare but severe food-borne disease that predominantly affects pregnant women, the unborn, newborns, the elderly and immunocompromised people. Following a large outbreak in the 1980 , specific food safety advice was provided to pregnant women and the immunocompromised in the United Kingdom. Following two coincident yet unconnected cases of pregnancy-related listeriosis in eastern European women in 2008, a review of the role of ethnicity in pregnancy-related listeriosis in England and Wales was undertaken in 2009. Cases reported to the national listeriosis surveillance scheme were classified as 'ethnic', belonging to an ethnic minority, or 'non-ethnic' based on their name, and trends were examined. Between 2001 and 2008, 1,510 cases of listeriosis were reported in England and Wales and, of these, $12 \%$ were pregnancy-related cases. The proportion of pregnancy-related cases classified as ethnic increased significantly from $16.7 \%$ to $57.9 \%$ (chi-square test for trend $\mathrm{p}=0.002$ ). The reported incidence among the ethnic population was higher than that among the non-ethnic population in 2006, 2007 and 2008 (Relative Risk: 2.38, 95\% confidence interval: 1.07 to $5.29 ; 3.82,1.82$ to $8.03 ; 4.33,1.74$ to 10.77 , respectively). This effect was also shown when analysing data from January to September 2009, using extrapolated live births as denominator. Increased immigration and/or economic migration in recent years appear to have altered the population at risk of pregnancy-related listeriosis in England and Wales. These changes need to be taken into account in order to target risk communication strategies appropriately.

\section{Introduction}

Listeriosis is a rare but severe bacterial disease that predominantly affects pregnant women, the unborn, newborns, the elderly and immunocompromised individuals. In newborns, the elderly and immunocompromised individuals, the disease usually manifests as meningitis and/or septicaemia, with high mortality rates reported amongst these risk groups. Listeriosis is mainly transmitted via the consumption of foods contaminated with Listeria monocytogenes and recent estimates suggest that listeriosis is the greatest cause of food-related deaths in the United Kingdom (UK) [1]. It has been reported that pregnant women have a 12-fold increased risk of developing disease after the consumption of contaminated food when compared with the general population [2], indicating that pregnancy may constitute a disposition to acquiring listeriosis. Pregnant women rarely have central nervous system infection [3] but may experience fever, miscarriage, premature delivery or stillbirth. Pregnant women infected with L. monocytogenes may also be asymptomatic.

While most pregnancy-related infections are detected during the third trimester, listeriosis can develop at any time during pregnancy and, in some instances, asymptomatic pregnant women may still pass on infection to the fetus. Pregnancy-related cases of listeriosis are divided into early and late onset. An early onset case is defined as a newborn with symptoms at birth or within 48 hours of birth resulting from in utero infection from the mother. The term late onset is applied when a newborn develops symptoms more than 48 hours after birth and such infections are thought to be predominantly the result of infection during passage through the birth canal. While rare, there have also been reports of late onset cases being a consequence of nosocomial transmission via indirect contact with early onset cases, for example through common birthing staff or equipment $[4,5]$. Newborns born with listeriosis and who survive may have complications that include physical retardation and granulomatosis infantiseptica (pyogenic nodules distributed systemically).

Between 1985 and 1989, the number of cases of listeriosis in England, Wales and Northern Ireland nearly doubled before rapidly declining in 1990 [6].This upsurge in cases was, however, mainly caused by an outbreak which disproportionately affected pregnant women, and was related with consumption of pâté produced by a single manufacturer [7]. The suspension of sales of pâté from this manufacturer, whose pâté was highly contaminated with subtypes of L. monocytogenes indistinguishable from those isolated from cases, coincided with the dissemination of two government health warnings in 1989: one with regards to 
the general risk of listeriosis and pâté [8] and a second one specifically targeted at vulnerable groups, which were defined at the time as pregnant women and people with impaired resistance to infection [9]. The aforementioned rapid decline in cases followed the second of these warnings.

The outbreak highlighted the risk to pregnant women of developing listeriosis after consuming pâté and reiterations of the health advice with regards to pâté and other high-risk foods still target this group [10]. Following two coincident but unconnected cases of pregnancy-related listeriosis in women of eastern European nationality during 2008, a review of pregnancy-related cases of listeriosis between 2001 and 2008 was undertaken using national surveillance data for England and Wales, to assess the role of ethnicity in this population and examine trends. A provisional investigation of cases between January and September 2009 was also carried out.

\section{Methods}

The Health Protection Agency Centre for Infections coordinates the surveillance of listeriosis in England and Wales. Cases are ascertained by the voluntary electronic reporting of laboratory-diagnosed cases and/or the referral of cultures for identification and subtyping. Epidemiological and microbiological data reported by these systems are combined, de-duplicated, and stored in a bespoke Microsoft Access 2003 database. Since 2005, supplementary clinical data are sought routinely from the consultant medical microbiologist responsible for the case, including onset date, date of hospital admission, principal listeria illness, clinical outcome, antibiotics and other drugs administered and symptoms [11]. In addition, exposure data with regards to travel, food consumption and food retailers are sought from the case or a relative of the case by environmental health officers in liaison with local health protection staff, using a standard exposure questionnaire [11]. Postcode data are employed to estimate socio-economic status using quintiles [12] of established indices of multiple deprivation [13].

A case of listeriosis is defined as an individual presenting with clinically compatible illness and from whom L. monocytogenes was isolated from a normally sterile site. Cases are classified as either nonpregnancy-related in individuals over four weeks old, or pregnancy-related where a mother and/or fetus/ newborn of less than four weeks old are affected. An affected mother and newborn are classified as one pregnancy-related case. Pregnancy-related cases that involve a live birth are routinely stratified further into early and late onset cases, as described above.

All cases of listeriosis are routinely classified as either 'ethnic' (belonging to an ethnic minority) or 'non-ethnic' (not belonging to an ethnic minority) based on their first name and surname, where available. This classification is in addition to case-reported ethnicity, reported via the standard exposure questionnaire since
2005 and based on the 2001 UK census classification [14]. Name-based classification was used throughout the study period from 2001 to 2008 , and used in analyses, while case-reported ethnicity data, were used to validate the name-based approach only. The numbers of live births, recorded in England and Wales from 2001 to 2008 and stratified by country of birth of mother, were obtained from the Office for National Statistics [15] and used as denominator data. The number of live births (i.e. not including stillbirths, miscarriages and abortions) to mothers who were born outside of the UK was used for comparative analyses with the number of pregnancy-related cases that were classified as ethnic, using the name-based approach. Similarly, the number of live births to mothers born in the UK was used for comparative analyses with the number of pregnancyrelated cases that were classified as non-ethnic. Both denominator datasets included live births to mothers whose usual residence was outside of the UK, accounting for $1.1 \%$ of live births to mothers who were born outside the UK and $0.2 \%$ of live births to mothers born in the UK.

Statistical analyses were carried out using Stata version 10 and Epi Info. Trends in proportions were investigated using the chi-square test for trend while differences in proportions employed the chi-square test and Fisher's exact test as appropriate. Relative risks (RR) and corresponding 95\% confidence intervals (Cl) were calculated. Poisson regression was employed for multivariable analysis: incidence in pregnancyrelated cases belonging to an ethnic minority, relative to pregnancy-related cases not belonging to an ethnic minority, were calculated whilst controlling for trend over the surveillance period. A log-link function was included to control for differences in the underlying population-live births to mothers born outside and inside the UK respectively in each year.

Linear regression models were fitted to live births to mothers born outside and inside the UK data for January to September, 2001 to 2008, and predictions (with corresponding 95\% prediction intervals) for this denominator population were obtained for 2009 based on the linear trend of the previous years. For 2009, the RR was estimated using the number of provisional cases between January and September and estimated denominator predictions for this period. An uncertainty interval around the RR was calculated based on the $\mathrm{Cls}$ calculated for the upper and lower prediction intervals.

\section{Results}

\section{Study population}

Between 2001 and 2008, 1,510 cases of listeriosis were reported in England and Wales and, of these, $12 \%$ were pregnancy-related. The proportion of cases that were pregnancy-related did not change during the study period (chi-square test for trend $p=0.866$; Figure). Of all cases reported, $12.3 \%$ were classified as ethnic cases, $86.7 \%$ as non-ethnic cases and the remaining $1 \%$ could not be classified as ethnic or non-ethnic by 
their name. Of the 181 pregnancy-related cases, $36.5 \%$ had ethnic names while $63 \%$ did not. One case in 2005 did not have a recorded name and, hence, ethnicity could not be established. This case was therefore not considered in these analyses. The proportion of pregnancy-related cases classified as having ethnic names over the whole study period was greater than that for non pregnancy-related cases (37\% vs. $9 \%$ respectively; chi-square test $p<0.001$ ).

\section{Incidence}

Amongst pregnancy-related cases, there was a significant increase in the proportion of cases classified as ethnic, from $16.7 \%$ to $57.9 \%$ (chi-square test for trend $\mathrm{P}=0.002$ ), during the study period (Figure). This change in proportion was not observed for non-pregnancyrelated cases (chi-square test for trend $p=0.124$ ). The increasing proportion of pregnancy-related cases classified as ethnic was most noticeable in 2006, 2007 and 2008, during which years the reported incidences of ethnic cases were higher than that expected in the underlying population (RR: $2.38,95 \% \mathrm{Cl}: 1.07$ to 5.29 ; $3.82,1.82$ to $8.03 ; 4.33,1.74$ to 10.77 ; respectively) (Table 1). Poisson regression indicated that there was

\section{FIGURE}

Total number of listeriosis cases $(n=1,510)$, proportion of cases that are pregnant and proportion of pregnant cases classified as ethnic ${ }^{\mathrm{a}}$, England and Wales, 2001-2008

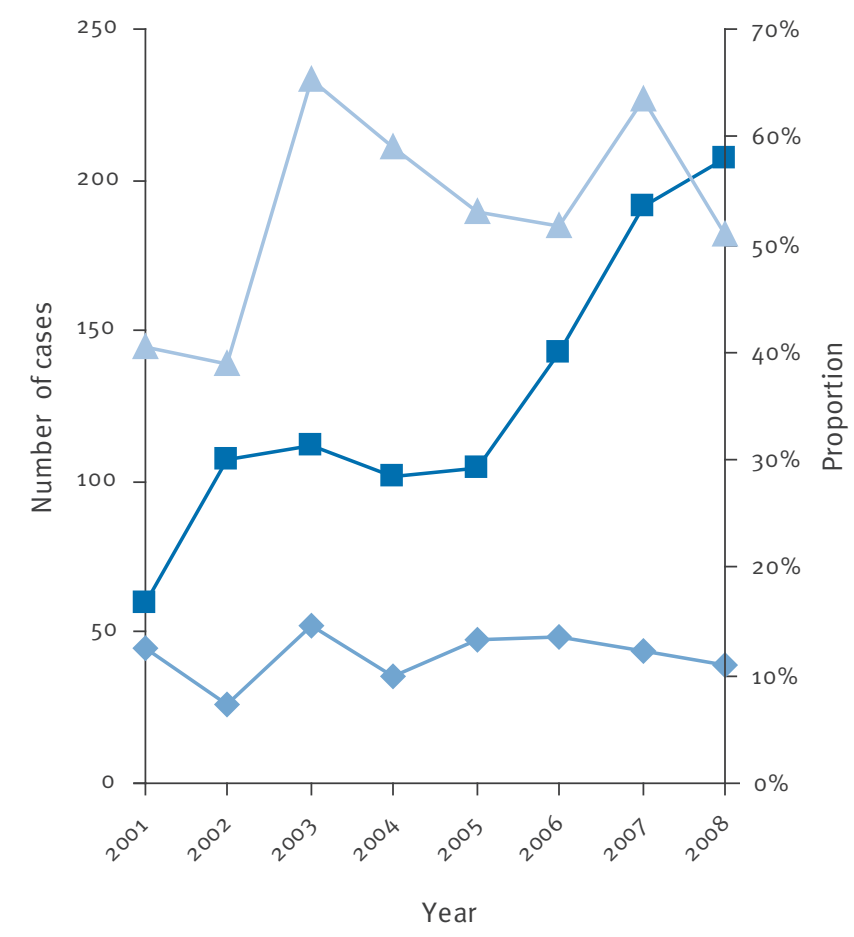

- Number of listeriosis cases

$\downarrow$ Proportion of listeriosis cases that are pregnant

- Proportion of listeriosis cases that are pregnant and classified as ethnic ${ }^{a}$

a Cases were classified as either ethnic or non-ethnic based on their name. a significant increase in incidence of ethnic cases after adjusting for the trend observed over the study period (RR: $2.25,95 \% \mathrm{Cl}: 1.66$ to 3.05 ).

Pregnancy-related cases classified as ethnic and reported between 2006 and 2008 (the years with an observed significant increase) were distributed across eight of nine regions in England and in Wales. A greater proportion of these pregnancy-related cases classified as ethnic were reported in London $(47.2 \%$ of all ethnic cases in England and Wales vs. $11.1 \%$ of all non-ethnic cases) when compared with elsewhere (52.7\% vs. $88.9 \%$; chi-square test $p<0.001)$. This level was above that expected, based on the number of live births in London during this period (RR: $3.66,95 \% \mathrm{Cl}: 1.23$ to 10.89). Based on provisional case data for January to September 2009 (16 ethnic cases and 10 non-ethnic cases) and extrapolated live births denominator data for the same period $(425,495$ live births to mothers born within the UK and 128,148 live births to mothers born outside of the UK), there remains an increased risk associated with ethnic minorities for this period (RR: 5.31, 95\% uncertainty interval: 2.33 to 12.20). All subsequent analyses relate to pregnancy-related cases, henceforth referred to as 'cases'.

\section{Clinical data}

There was no significant difference in the proportion of clinical questionnaires returned for ethnic and nonethnic cases ( $91 \%$ vs. $94 \%$ respectively; Fisher's exact test $p=0.553)$. There was also no difference in the proportion of infecting serotypes that were $1 / 2$ compared with 4 between ethnic and non-ethnic cases (31\% vs. $24 \%$ respectively; chi-square test $p=0.390)$. When characteristics of ethnic and non-ethnic cases with a returned clinical questionnaire were compared, there was no significant difference in the recorded outcome of pregnancy, newborn survival, the stage of onset of symptoms in the newborn (early vs. late onset) or presentation with either meningitis or septicaemia in the newborn (Table 2). However, newborns born to ethnic mothers were more likely to present with symptoms of listeriosis at birth (chi-square test $p=0.039$ ) and these cases were more likely to come from more deprived areas (chi-square test for trend p<0.001), with almost half of the ethnic cases belonging to the most deprived group (Table 3 ).

\section{Exposure data}

There was no significant difference in the proportion of exposure questionnaires returned for ethnic and nonethnic cases ( $58 \%$ vs. $47 \%$ respectively; chi-square test $p=0.285$ ). Of the 37 cases for which exposure and clinical data were available, 18 were classed as ethnic on the basis of their name. The cases defined as ethnic were more likely to describe their own ethnicity as 'non-white British', i.e. as something other than white British, compared with all cases (positive predictive value $94.4 \%$ and negative predictive value $68.4 \%$ )(Table 3 ). No single country or group of countries (e.g. countries within the Indian sub-continent) 
predominated for cases who described themselves as non-white British (Table 4).

Cases defined as ethnic on the basis of their name were significantly more likely to consume pâté, cabbage or dill. In addition, they were more likely to shop in two national supermarket chains $A$ and $B$ or green grocers but less likely to shop in local bakeries (Table 5).

\section{Discussion}

We report a sustained increase in the incidence of pregnancy-related cases of listeriosis from ethnic

\section{TABLE 1}

Pregnancy-related listeriosis cases by name-based ethnicity classification ${ }^{a}(n=180)$, number of live births to mothers born outside $(n=1,055,827)$ and within the United Kingdom $(n=4,110,279)$ and related relative risks, England and Wales, 2001-2008

\begin{tabular}{|c|c|c|c|c|c|}
\hline Year & $\begin{array}{l}\text { Number of ethnic } \\
\text { pregnancy-related } \\
\text { listeriosis cases }\end{array}$ & $\begin{array}{c}\text { Number of live births to } \\
\text { mothers born outside } \\
\text { the UK }\end{array}$ & $\begin{array}{l}\text { Number of non-ethnic } \\
\text { pregnancy-related } \\
\text { listeriosis cases }\end{array}$ & $\begin{array}{l}\text { Number of live births to } \\
\text { mothers born in the UK }\end{array}$ & $\begin{array}{l}\text { Relative Risk ( } 95 \% \\
\text { confidence intervals) }\end{array}$ \\
\hline 2001 & 3 & 98,115 & 15 & 496,519 & $1.01(0.29-3.5)$ \\
\hline 2002 & 3 & 105,514 & 7 & 490,608 & $1.99(0.52-7.71)$ \\
\hline 2003 & 11 & 115,593 & 24 & 505,876 & $2.01(0.98-4.09)$ \\
\hline 2004 & 6 & 124,746 & 15 & 514,975 & $1.65(0.64-4.26)$ \\
\hline 2005 & 7 & 134,334 & 17 & 511,501 & $1.57(0.65-3.78)$ \\
\hline 2006 & 10 & 146,643 & 15 & 522,958 & $2.38(1.07-5.29)$ \\
\hline 2007 & 15 & 160,083 & 13 & 529,930 & $3.82(1.82-8.03)$ \\
\hline 2008 & 11 & 170,799 & 8 & 537,912 & $4.33(1.74-10.77)$ \\
\hline Total & 66 & $1,055,827$ & 114 & $4,110,279$ & \\
\hline
\end{tabular}

UK: United Kingdom.

${ }^{a}$ Cases were classified as either ethnic or non-ethnic based on their name.

\section{TABLE 2}

Characteristics of pregnancy-related listeriosis cases with a returned clinical questionnaire by name-based ethnicity classification ${ }^{\mathrm{a}}$, England and Wales, 2001-2008 (n=167)

\begin{tabular}{|c|c|c|}
\hline \multirow{2}{*}{ Factor } & \multicolumn{2}{|c|}{ Ethnicity of pregnancy-related listeriosis cases } \\
\hline & Ethnic & Non-ethnic \\
\hline & $(\mathrm{N}=60)$ & $(\mathrm{N}=107)$ \\
\hline \multicolumn{3}{|c|}{ Death related with pregnancy (miscarriage, stillbirth, or death) } \\
\hline Yes & $15 / 49$ & $22 / 81$ \\
\hline No & $34 / 49$ & $59 / 81$ \\
\hline \multicolumn{3}{|l|}{ Pregnancy Outcome } \\
\hline Live birth & $47 / 57$ & $71 / 91$ \\
\hline Miscarriage & $6 / 57$ & $16 / 91$ \\
\hline Stillbirth & $2 / 57$ & $3 / 91$ \\
\hline Still pregnant & $2 / 57$ & $1 / 91$ \\
\hline \multicolumn{3}{|l|}{ Survival of live births } \\
\hline Survived & $32 / 39$ & $53 / 56$ \\
\hline Died & $7 / 39$ & $3 / 56$ \\
\hline \multicolumn{3}{|l|}{ Onset type of live births } \\
\hline Early Onset ( $\leq 48$ hrs) & $28 / 38$ & $30 / 43$ \\
\hline Late Onset (>48hrs) & $10 / 38$ & $13 / 43$ \\
\hline \multicolumn{3}{|c|}{ Symptoms of listeriosis in newborns } \\
\hline Yes & $38 / 45$ & $40 / 60$ \\
\hline No & $7 / 45$ & $20 / 60$ \\
\hline \multicolumn{3}{|l|}{ Meningitis in newborns } \\
\hline Yes & $11 / 16$ & $3 / 6$ \\
\hline No & $5 / 16$ & $3 / 6$ \\
\hline \multicolumn{3}{|c|}{ Septicaemia in newborns } \\
\hline Yes & $14 / 17$ & $12 / 15$ \\
\hline No & $3 / 17$ & $3 / 15$ \\
\hline
\end{tabular}

a Cases were classified as either ethnic or non-ethnic based on their name, 'unknowns' were excluded in these analyses. 
minorities in England and Wales between 2006 and 2008 , with provisional case data suggesting that this increase continued into 2009 when compared with estimated population data. This increase was not observed amongst non pregnancy-related cases. An increase in pregnancy-related listeriosis in women born outside of the country was reported in Ireland in late 2007 [16]. Listeriosis has also been reported as

\section{TABLE 3}

Socio-economic status of pregnancy-related listeriosis cases with a returned clinical questionnaire by name-based ethnicity classification ${ }^{\mathrm{a}}$, England and Wales, 2001-2008 (n=161)

\begin{tabular}{|c|c|c|c|c|}
\hline Socio-economic status & 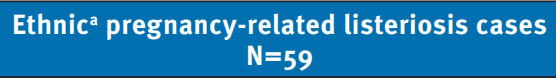 & $\%$ & $\begin{array}{l}\text { Non-ethnic }{ }^{\mathrm{a}} \text { of pregnancy-related listeriosis cases } \\
\qquad \mathrm{N}=102\end{array}$ & $\%$ \\
\hline IMD 1 (least deprived) & $4 / 59$ & 7 & $19 / 102$ & 19 \\
\hline IMD 2 & $4 / 59$ & 7 & $26 / 102$ & 25 \\
\hline$I_{3}$ & $8 / 59$ & 14 & $6 / 102$ & 6 \\
\hline IMD 4 & $15 / 59$ & 25 & $24 / 102$ & 24 \\
\hline IMD5 (most deprived) & $28 / 59$ & 47 & $27 / 102$ & 26 \\
\hline
\end{tabular}

IMD: Indices of Multiple Deprivation [12].

aCases were classified as either ethnic or non-ethnic based on their name, 'unknowns' were excluded in these analyses.

\section{TABLE 4}

Case-reported ethnicity data (as per 2001 census classification system) of pregnancy-related listeriosis cases by name-based ethnicity classification ${ }^{a}$, England and Wales, 2005-2008 (n=37)

\begin{tabular}{|l|c|c|}
\hline \multirow{2}{*}{ Case-reported ethnicity } & \multicolumn{2}{|c|}{ Name-based ethnicity } \\
\cline { 2 - 3 } White (British) & $1 / 18$ & Non-ethnic ${ }^{\mathrm{a}}$ (N=19) \\
\hline White (Non-British) & $5 / 18 / 19$ \\
\hline Black African & $2 / 18$ & $2 / 19$ \\
\hline White/Black Caribbean & $0 / 18$ & $1 / 19$ \\
\hline Indian & $4 / 18$ & $1 / 19$ \\
\hline Pakistani & $1 / 18$ & $1 / 19$ \\
\hline Chinese & $1 / 18$ & $0 / 19$ \\
\hline Other Asian & $2 / 18$ & $0 / 19$ \\
\hline Other Ethnic & $2 / 18$ & $1 / 19$ \\
\hline Total (other than white British) & $17 / 18$ & 0 \\
\hline
\end{tabular}

a Cases were classified as either ethnic or non-ethnic based on their name, 'unknowns' were excluded in these analyses.

\section{TABLE 5}

Food history of pregnancy-related listeriosis cases by name-based ethnicity classification ${ }^{\text {a }}$, England and Wales, 2005-2008 $(\mathrm{n}=37)$

\begin{tabular}{|c|c|c|c|}
\hline Food history & $\begin{array}{l}\text { Ethnic }^{\text {a }} \text { pregnancy-related listeriosis cases } \\
\qquad(n=18)\end{array}$ & $\begin{array}{l}\text { Non-ethnic }{ }^{a} \text { pregnancy-related listeriosis cases } \\
\qquad(n=19)\end{array}$ & p-value \\
\hline Consumption of pâté & $5 / 18$ & $0 / 19$ & $0.020^{b}$ \\
\hline Consumption of cabbage & $8 / 16$ & $1 / 19$ & $0.005^{b}$ \\
\hline Consumption dill & $5 / 16$ & $0 / 18$ & $0.016^{b}$ \\
\hline $\begin{array}{l}\text { Shopped in national } \\
\text { supermarket chain A }\end{array}$ & $4 / 18$ & $0 / 19$ & $0.046^{b}$ \\
\hline Shopped at green grocers & $7 / 18$ & $0 / 19$ & $0.003^{b}$ \\
\hline Shopped at local bakeries & $3 / 18$ & $9 / 19$ & $0.046^{c}$ \\
\hline
\end{tabular}

a Cases were classified as either ethnic or non-ethnic based on their name, 'unknowns' were excluded in these analyses.

${ }^{b}$ Fisher's exact test.

c Chi-square test. 
disproportionately affecting pregnant Hispanic women in the United States $[17,18]$ and pregnant women living in a household where a language other than English was spoken in Australia [19]. To the authors' knowledge, the sustained increase reported in this study has not been previously described elsewhere. Pregnancyrelated listeriosis cases comprise the minority of what is already a rare disease, and by this very nature any changes in incidence trends within this population will only become evident after a number of years.

Differences in health seeking behaviour and access to healthcare between ethnic minorities and the general population may impact on our incidence estimates, but this is difficult to assess. It is reasonable to assume that new migrants to the UK may find it more difficult to access the existing healthcare services than UK residents.

There appears to be no differential ascertainment of clinical and exposure data between ethnic and nonethnic cases which minimises the likelihood of this form of bias affecting our findings. Analyses performed on those cases with a completed clinical questionnaire returned indicate that, compared to non-ethnic cases, ethnic cases were more likely to be from more deprived areas and newborns more often displayed symptoms of listeriosis at birth. It has previously been established that ethnic minorities reside disproportionately in more deprived areas [20] and this would explain the distribution of these pregnancy-related cases. Differential symptom presentation at birth may reflect differences in gestational age at time of infection (i.e. trimester) or route of infection (in utero or during passage through the birth canal) between ethnic and non-ethnic cases but this needs further investigation. Furthermore, we could not assess any differences in terms of clinical characteristics and exposures amongst those that did not have a completed clinical or exposure questionnaire returned in our analyses.

Cases' own description of their ethnic background was used to validate the name-based classification method of ethnicity employed in this study. The negative predictive value for this approach indicates that approximately $30 \%$ of cases defined as non-ethnic report their own ethnicity as something other than white British. Consequently, the number of pregnancy-related cases defined by their name as ethnic seems to underestimate the number of those belonging to an ethnic group other than white British. Therefore, the risk of pregnancy-related listeriosis associated with ethnic minorities is likely to be greater than that reported here. Regardless, any misclassification is likely to be nondifferential over the study period and would therefore not affect the observed increase in pregnancy-related listeriosis in the ethnic group.

The reporting of certain foods and retail exposures differed between ethnic pregnancy-related cases and non-ethnic pregnancy-related cases. However, it is important to note that comparisons are not being made with controls without illness and hence, findings should not be considered as risk factors for infection [21]. Furthermore, such case-case comparisons would not indicate the magnitude or direction of risk among pregnancy-related cases and should only be used for hypothesis generation, which then need to be tested by alternative methodologies. If exposures were common to both ethnic and non-ethnic groups, they would have been underestimated or, indeed, would have remained unidentified using this method. It is important to bear in mind that ethnic minorities are a heterogeneous group who likely vary in their food preferences and behaviours. The sample size of this study did not allow for analyses of strata within this group. Nevertheless, the consumption of pâté was reported more commonly by ethnic than non-ethnic pregnancy-related cases, suggesting that food safety advice issued by the UK government is not reaching this at-risk population or is not being followed.

Incidence was calculated by comparing cases classed as ethnic or non-ethnic with the numbers of live births by country of origin of mother (non-UK born and UK born respectively). Differences between the numerator and the denominator may have affected the accuracy of our risk estimates. Firstly, live birth data will exclude instances of stillbirth or miscarriage - these are both included in the numerator - and, consequently, the risk of listeriosis will be over estimated. The denominator data employed in the analyses also included mothers whose usual country of residence was outside of the UK, while cases living outside the UK are not reported to this surveillance scheme and would not be represented in this numerator. While these mothers represent only a small proportion of the total, inflation of the denominator will lead to some underestimation of risk. The final, and perhaps most important, consideration is that the numerator refers to cases (mothers/ newborns/both) stratified by ethnicity whereas the denominator refers to live births to mothers stratified by country of birth. A mother could, however, be born in the UK and belong to an ethnic minority but this was the best available proxy for ethnicity of mothers of live births. While there are limitations to using live birth data by country of origin of mother, there was a need to assess the observed increasing trend in the context of population change, and our study suggests that the increase in incidence is over and above what would be expected.

\section{Conclusions}

Increased immigration and/or economic migration in recent years appear to have altered the population most at risk of pregnancy-related listeriosis in England and Wales. The increase in the number of pregnancyrelated cases belonging to an ethnic minority has disproportionately affected London, where migration has directly increased the number of new births in some local authorities [22]. Passive food safety messages, which highlight high-risk foods, appear not to be 
reaching pregnant women from ethnic minorities or are not being followed by this emerging at-risk population. More specific and targeted routes of communication and materials, which should be both culturally-relevant and in a range of appropriate languages, are needed. Our findings should be considered by those targeting risk communication strategies to vulnerable groups. Studies to identify which ethnic minorities are most at risk would provide further valuable information on how to more effectively tailor communication strategies.

\section{Acknowledgements}

Thanks are extended to the hospital microbiologists, environmental health officers and public health professionals who contribute to this surveillance system.

\section{References}

1. Food Standards Agency (FSA). Annual Report of the Chief Scientist 2006/7. London: FSA; 2007. Available from: http:// www.food.gov.uk/multimedia/pdfs/board/fsa071005a.pdf

2. Hof H. History and epidemiology of listeriosis. FEMS Immunol Med Microbiol. 2003; 35(3):199-202.

3. McLauchlin J. Human listeriosis in Britain, 1967-85, a summary of 722 cases. 1. Listeriosis during pregnancy and in the newborn. Epidemiol Infect. 1990; 104(2):181-9.

4. Nelson KE, Warren D, Tomasi AM, Raju TN, Vidyasagar D. Transmission of neonatal listeriosis in a delivery room. Am J Dis Child. 1985;139(9):903-5.

5. Schuchat A, Lizano C, Broome CV, Swaminathan B, Kim C, Winn K. Outbreak of neonatal listeriosis associated with mineral oil. Pediatr Infect Dis J. 1991;10(3):183-9.

6. Gilbert RJ, Hall SM, Taylor AG. Listeriosis update. PHLS Microbiol Digest. 1989; 6:33-7.

7. McLauchlin J, Hall SM, Velani SK, Gilbert RJ. Human listeriosis and pate: a possible association. BMJ. 1991; 303(6805):773-5.

8. United Kingdom Department of Health (DH). Listeria found in pate. London: DH. 1989.

9. United Kingdom Department of Health (DH). Advice to vulnerable groups on pate stands. London: DH. 1989.

10. Food Standards Agency (FSA). Pregnancy. London: FSA. [Accessed 15 September 2009]. Available from: http://www. eatwell.gov.uk/asksam/agesandstages/pregnancy/

11. Health Protection Agency (HPA). Questionnaires for the surveillance of Listeria monocytogenes infection in England \& Wales. London: HPA; 8 August 2008. Available from: http://www.hpa.org.uk/Topics/InfectiousDiseases/ InfectionsAZ/Listeria/EpidemiologicalData/ listeQuestionnairesforthesurveillanceofListeria

12. Gillespie IA, Mook P, Little CL, Grant K, McLauchlin J. Human listeriosis in England, 2001-2007: association with neighbourhood deprivation. Euro Surveill. 2010;15(27):pii=19609. Available from: http://www. eurosurveillance.org/ViewArticle.aspx?Articleld=19609

13. Department of Communities and Local Government. Indices of Deprivation 2007. London. [Accessed 5 March 2009]. Available from: http://www.communities.gov.uk/communities/ neighbourhoodrenewal/deprivation/deprivationoz/

14. Office for National Statistics. Census 2001. England Household Form. Available from: http://www.statistics.gov.uk/ census2001/pdfs/H1.pdf

15. Office for National Statistics. Summary of key live birth statistics. Available from: http://www.statistics.gov.uk/ downloads/theme_population/Table_1.xls

16. Health Protection Surveillance Centre (HPSC). Increase in Listeriosis in Ireland, 2007.Epi Insight. 2007; 8(12). Available from: http://www.ndsc.ie/hpsc/EPI-Insight/Volume82007/ File,2613,en.PDF

17. Jackson KA, Iwamoto M, Swerdlow D. Pregnancy-associated listeriosis. Epidemiol Infect. 2010;1-7. [Epub ahead of print]

18. Voetsch AC, Angulo FJ, Jones TF, Moore MR, Nadon C, McCarthy $P$, et al. Reduction in the incidence of invasive listeriosis in foodborne diseases active surveillance network sites, 1996 2003. Clin Infect Dis. 2007; 44(4):513-20.
19. Dalton CB, Merritt TD, Unicomb LE, Kirk MD, Stafford RJ, Lalor K, et al. A national case-control study of risk factors for listeriosis in Australia. Epidemiol Infect. 2010;1-9. [Epub ahead of print]

20. Tinsley J, Jacob M. Deprivation and Ethnicity in England: A Regional Perspective. Regional Trends. 2006; 39:19-28.

21. McCarthy N, Giesecke J. Case-case comparisons to study causation of common infectious diseases. Int J Epidemiol. 1999; 28(4):764-8.

22. London Health Observatory. Estimating future births in the capital: a discussion document. Executive summary. 2008. [Accessed 13 Aug 2009]. Available from: www.lho.org.uk/ viewResource.aspx?id=14281 